Comparison between static chamber and tunable diode laser-based eddy covariance techniques for measuring nitrous oxide fluxes from a cotton field

Wang, Kai

2013-04-15

Wang , K, Zheng , X, Pihlatie , M , Vesala , T , Liu , C , Haapanala , S , Mammarella , I, Rannik, U \& Liu , H 2013 , ' Comparison between static chamber and tunable diode laser-based eddy covariance techniques for measuring nitrous oxide fluxes from a cotton field ' , Agricultural and Forest Meteorology , vol. 171 , pp. 9-19 . https://doi.org/10.1016/j.agrformet.2012.11.009

http://hdl.handle.net/10138/40049

https://doi.org/10.1016/j.agrformet.2012.11.009

publishedVersion

Downloaded from Helda, University of Helsinki institutional repository.

This is an electronic reprint of the original article.

This reprint may differ from the original in pagination and typographic detail.

Please cite the original version. 


\title{
Comparison between static chamber and tunable diode laser-based eddy covariance techniques for measuring nitrous oxide fluxes from a cotton field
}

\author{
Kai Wanga,b, Xunhua Zheng ${ }^{\mathrm{a}, *}$, Mari Pihlatie ${ }^{\mathrm{b}}$, Timo Vesala ${ }^{\mathrm{b}}$, Chunyan Liu ${ }^{\mathrm{a}}$, Sami Haapanala $^{\mathrm{b}}$, \\ Ivan Mammarellab ${ }^{\mathrm{b}}$, Üllar Rannik ${ }^{\mathrm{b}}$, Huizhi Liu ${ }^{\mathrm{a}}$

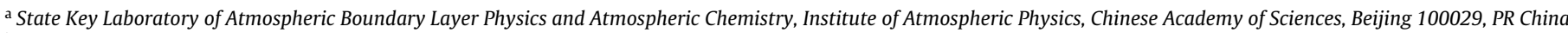 \\ ${ }^{\mathrm{b}}$ Department of Physics, University of Helsinki, Finland, P.O. Box 48, FI-00014 University of Helsinki, Finland
}

\section{A R T I C L E I N F O}

\section{Article history:}

Received 27 December 2011

Received in revised form

16 November 2012

Accepted 17 November 2012

\section{Keywords:}

Nitrous oxide

Direct emission factor

Chamber

Eddy covariance

Cropland

\begin{abstract}
A B S T R A C T
Nitrous oxide $\left(\mathrm{N}_{2} \mathrm{O}\right)$ fluxes from a cotton field in northern China were measured for a year using the static chamber method based on a gas chromatograph (GC) and the eddy covariance (EC) technique based on a tunable diode laser (TDL). The aims were to compare the $\mathrm{N}_{2} \mathrm{O}$ fluxes obtained from both techniques, assess the uncertainties in the fluxes and evaluate the annual direct emission factors $\left(E F_{\mathrm{d}} \mathrm{s}\right.$, i.e. the loss rate of fertilizer nitrogen via $\mathrm{N}_{2} \mathrm{O}$ emission) using the year-round datasets. During the experimental period, the hourly and daily mean chamber fluxes ranged from 0.6 to 781.8 and from 1.2 to $468.8 \mu \mathrm{g} \mathrm{N} \mathrm{m}^{-2} \mathrm{~h}^{-1}$, respectively. The simultaneously measured daily mean EC fluxes varied between -10.8 and $912.0 \mu \mathrm{g} \mathrm{N} \mathrm{m}^{-2} \mathrm{~h}^{-1}$. The EC measurements only provided trustworthy 30 -min fluxes during high-emission period (a 20-day period immediately after the irrigation that followed the nitrogen fertilization event). A reliable comparison was confined to the high-emission period and showed that the chamber fluxes were 17-20\% lower than the EC fluxes. This difference may implicate the magnitude of systematic underestimation in the fluxes from chamber measurements. The annual emission from the fertilized cotton field was estimated at $1.43 \mathrm{~kg} \mathrm{Nha}^{-1} \mathrm{yr}^{-1}$ by the chamber observations and $3.15 \mathrm{~kg} \mathrm{Nha}^{-1} \mathrm{yr}^{-1}$ by the EC measurements. The $E F_{\mathrm{d}} \mathrm{S}$ calculated from the chamber and EC data were $1.04 \%$ and $1.65 \%$, respectively. The chamber-based estimate was very close to the default value (1.0\%) recommended by the Intergovernmental Panel on Climate Change. However, the difference in the $E F_{\mathrm{d}} S$ based on the two measurement techniques may vary greatly with changing environmental conditions and management practices. Further comparison studies are still needed to elucidate this issue.
\end{abstract}

(c) 2012 Elsevier B.V. All rights reserved.

\section{Introduction}

The global atmospheric concentration of nitrous oxide $\left(\mathrm{N}_{2} \mathrm{O}\right)$ has increased from $270 \mu \mathrm{LL}^{-1}$ (i.e., ppbv) during the pre-industrial period to 319 ppbv in 2005 (IPCC, 2007). Nitrous oxide is an important greenhouse gas due to its long lifetime and strong positive radiative forcing. A recent study suggested that the anthropogenic release of $\mathrm{N}_{2} \mathrm{O}$ is currently the most important ozone-depleting substance and is expected to remain the largest throughout the 21st century (Ravishankara et al., 2009). Agricultural soils play an important role in the global $\mathrm{N}_{2} \mathrm{O}$ budget, accounting for approximately $42 \%$ of the anthropogenic $\mathrm{N}_{2} \mathrm{O}$ emissions (IPCC, 2007). Those emissions are mostly associated with the intensive use of nitrogen fertilizers. However, a large uncertainty remains in the "bottomup" estimation of the anthropogenic contribution (Crutzen et al., 2008; IPCC, 1997, 2006). The "bottom-up" calculation of regional

\footnotetext{
* Corresponding author. Tel.: +86 10 82083810; fax: +8610 62041393.

E-mail address: xunhua.zheng@post.iap.ac.cn (X. Zheng).
}

or global direct $\mathrm{N}_{2} \mathrm{O}$ emissions relies heavily on the direct emission factors $\left(E F_{\mathrm{d}} \mathrm{s}\right.$, defined as the nitrogen loss rates of the amended fertilizer nitrogen via $\mathrm{N}_{2} \mathrm{O}$ emission) that result from static chamber measurements based on gas chromatograph (GC) analysis, which have very high uncertainties (IPCC, 1997; Stehfest and Bouwman, 2006). The static chamber technique is thought to bias the actual $\mathrm{N}_{2} \mathrm{O}$ fluxes due to the drawbacks of the technique itself. This problem has been widely discussed in previous studies (e.g., Livingston and Hutchinson, 1995; Rochette and Eriksen-Hamel, 2008; Venterea et al., 2009; Levy et al., 2011), whereas few studies have compared the $\mathrm{N}_{2} \mathrm{O}$ fluxes measured using the static chambers and other measurement techniques (Smith et al., 1994; Christensen et al., 1996; Laville et al., 1999; Pihlatie et al., 2005, 2010; Neftel et al., 2007, 2010; Desjardins et al., 2010; Jones et al., 2011). To better understand the uncertainties in chamber-based $E F_{\mathrm{d}} \mathrm{S}$ so as to improve regional and global $\mathrm{N}_{2} \mathrm{O}$ emission inventories, additional studies are needed to provide field-based and long-term assessments of the comparability of the $\mathrm{N}_{2} \mathrm{O}$ fluxes and the $E F_{\mathrm{d}} \mathrm{S}$ obtained from chamber and other techniques, such as eddy covariance (EC). 
(a)

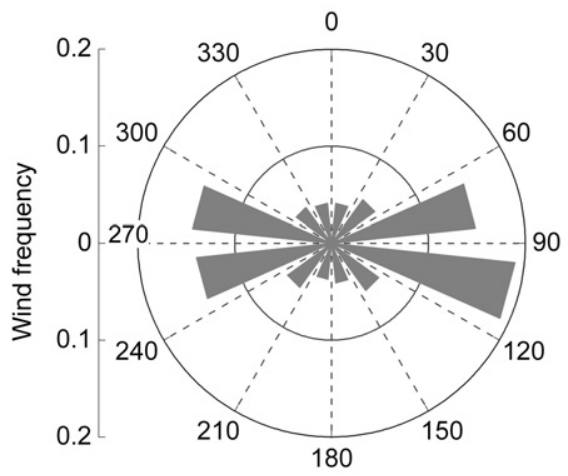

(b)

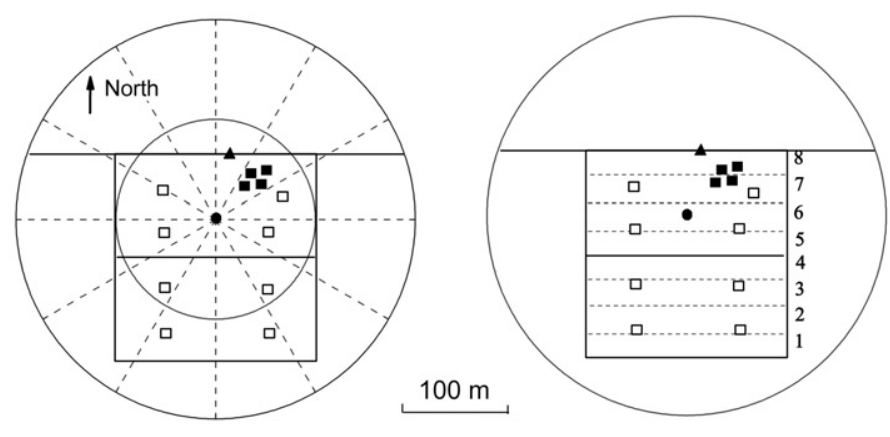

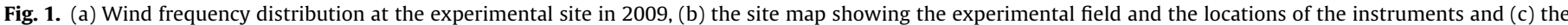

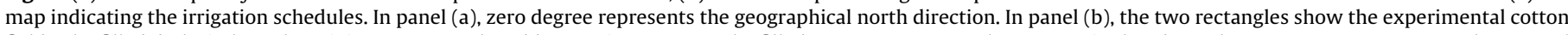

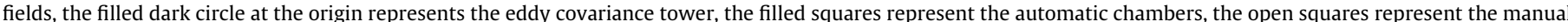

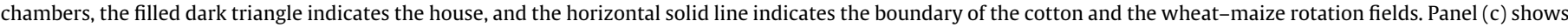
the eight belt areas of the experimental field, which were irrigated in the order 1, 5, 2, 6, 3, 7, 4 and 8 during each irrigation event.

The static chamber technique is simple in concept and operation. Also, chambers are flexible and allow observations on small field plots (meter scale) or complex terrains. However, chambers are subject to several drawbacks. First, the chamber deployment may influence the concentration gradient between the soil and the atmosphere and as a consequence can decrease the flux from the soil (Livingston and Hutchinson, 1995; Davidson et al., 2002; Kutzbach et al., 2007). Second, the most commonly used manual chamber method may easily bias the estimates of seasonal and annual emissions due to low temporal resolution (Smith and Dobbie, 2001; Zheng et al., 2004). However, this problem is less crucial for automatic chambers due to its ability in taking continuous diurnal measurements (Butterbach-Bahl et al., 1997; Yao et al., 2009). Finally, the fluxes may be under- or overestimated if the chambers are placed on a "cold spot" or "hot spot" due to the spatial variability of agricultural soils, especially when the number of chambers is small (Ambus and Christensen, 1994).

The EC technique is the most direct micrometeorological method for measuring $\mathrm{N}_{2} \mathrm{O}$ fluxes. It measures the spatially averaged fluxes over an ecosystem at a large scale (e.g., $0.1-1 \mathrm{~km}^{2}$ ) without disturbing the environmental conditions. The EC method relies on high-frequency measurements of the vertical wind velocity and the $\mathrm{N}_{2} \mathrm{O}$ concentration. In recent years, the availability of fast-response detectors, such as the tunable diode laser (TDL) and the quantum cascade laser $(\mathrm{QCL})$, has enabled intensive EC measurements of $\mathrm{N}_{2} \mathrm{O}$ emissions from different terrestrial ecosystems (Edwards et al., 2003; Pihlatie et al., 2005; Neftel et al., 2007; Eugster et al., 2007; Jones et al., 2011). However, the EC method is based on several theoretical assumptions, e.g., fully developed turbulence, steady state conditions of flow and horizontal homogeneity. These assumptions do not always hold true during field experiments. For this reason, appropriate corrections (e.g., Wilczak et al., 2001) have to be performed, and extensive quality checks (e.g. Foken and Wichura, 1996; Foken et al., 2003) are needed to exclude low quality data that do not fulfill the theoretical assumptions. Additionally, when applying the EC method to measure $\mathrm{N}_{2} \mathrm{O}$ fluxes, there are a number of challenges, such as offset drift of $\mathrm{N}_{2} \mathrm{O}$ signals due to fringe effects (e.g., Mammarella et al., 2010), determination of the time lag between vertical wind and gas concentration (e.g., Pihlatie et al., 2005, 2010) and water vapor interference in the accuracy of flux measurements (e.g., Neftel et al., 2010).

To our knowledge, a long-term comparison of $\mathrm{N}_{2} \mathrm{O}$ emissions from intensively managed croplands measured using static chamber and EC techniques has not been reported. The aforementioned comparison studies were mostly based on short-term experiments covering only a few days or months and were mainly focused on critical periods (e.g., after nitrogen fertilization). In this study, $\mathrm{N}_{2} \mathrm{O}$ fluxes from an irrigated, fertilized cotton field were measured for a year using the automatic and manual static chamber methods and the TDL-based EC technique. Our purposes were to (a) compare the $\mathrm{N}_{2} \mathrm{O}$ fluxes obtained from both of the techniques and assess their uncertainties and (b) evaluate the annual $E F_{\mathrm{d}} \mathrm{s}$ using the year-round $\mathrm{N}_{2} \mathrm{O}$ datasets.

\section{Materials and methods}

\subsection{Field site description}

This study was conducted in 2009 in a conventional irrigated cotton field in Yuncheng, Shanxi Province, China $\left(34^{\circ} 55.50^{\prime} \mathrm{N}\right.$, $110^{\circ} 42.59^{\prime} \mathrm{E}$ ). The annual mean air temperature and precipitation over the past 10 years were $14.7^{\circ} \mathrm{C}$ and $508 \mathrm{~mm}$, respectively (National Meteorological Information Center of China Meteorology Administration, http://cdc.cma.gov.cn). The prevailing wind directions at the field site were from the east $\left(60-120^{\circ}\right)$ and west $\left(240-300^{\circ}\right)$ (Fig. 1a). Cotton (Gossypium spp.) is commonly cultivated in this region. The cotton plants can usually grow to a maximum height of $1 \mathrm{~m}$. The soil is classified as Mottlic Hapli-Ustic Argosols in the Chinese soil classification (Gong et al., 2007) or Calcic Cambisol in the international soil classification (IUSS Working Group WRB, 2006). The organic carbon and total nitrogen contents of the top layer $(0-10 \mathrm{~cm})$ were 10.0 and $1.1 \mathrm{~g} \mathrm{~kg}^{-1}$, respectively. The surface soil $(0-6 \mathrm{~cm})$ had a $\mathrm{pH}$ of 8.7 (water extract) and a bulk density of $1.20 \mathrm{~g} \mathrm{~cm}^{-3}$. There was a shallow groundwater table that varied between -1.5 and $-0.7 \mathrm{~m}$.

A map of the site is given in Fig. 1b. The experimental cotton field was $200 \mathrm{~m} \times 200 \mathrm{~m}$. Since 2004, the northern half has been continuously planted with cotton, whereas the southern half was rotated from sorghum to cotton in 2009. The areas around the experimental field were also planted with cotton except the area to the northern border, where winter wheat and summer maize have been grown in rotation since 2005. The equipment for the EC measurements was installed $70 \mathrm{~m}$ from the northern border and $100 \mathrm{~m}$ from both the eastern and western borders. The automatic chamber (AC) system was located approximately $60 \mathrm{~m}$ northeast of the EC mast. A house (length $\times$ width $\times$ height $=5 \mathrm{~m} \times 2.5 \mathrm{~m} \times 2.5 \mathrm{~m}$ ) was situated at the boundary of the two fields, where the gas samples from the chambers were analyzed online.

After the cotton and sorghum harvest in the winter of 2008, the residue and straw were shredded by machine and plowed into the 
soil at a depth of $0-30 \mathrm{~cm}$. The field was fallowed until the cotton seeds were sown on April 10 in the following year. The field was fertilized only once with urea at a rate of $75 \mathrm{~kg} \mathrm{~N} \mathrm{ha}^{-1} \mathrm{yr}^{-1}$ on June 28,2009 . A movable sprinkler was used to irrigate the experimental field with ground water on April 8, July 10 and August 21. The sprinkler could cover and irrigate a belt area of $200 \mathrm{~m} \times 25 \mathrm{~m}$. During each irrigation event, the eight belts of the field were irrigated in the order of $1,5,2,6,3,7,4$ and 8 , as numbered in Fig. 1c. The irrigation of each belt lasted for $6 \mathrm{~h}$; therefore, it usually took 2-3 days to complete the irrigation of the whole experimental field.

\subsection{Chamber measurements}

\subsubsection{Automatic chamber}

From January 1 to October 15 of 2009 , the $\mathrm{N}_{2} \mathrm{O}$ fluxes were measured using an AC system named AMEG (automatic chamber measuring system for emissions of trace gases). The system successfully measured the $\mathrm{N}_{2} \mathrm{O}$ fluxes from the same cotton field in 2008 and from the adjacent winter-wheat and summer-maize field (Fig. 1b) in 2007-2009 (Liu et al., 2010, 2011). In fact, the AMEG had twelve chambers running simultaneously, with four in the cotton field and the remaining chambers in the wheat-maize field. The four cotton chambers were distributed 5-10 $\mathrm{m}$ apart and $15-25 \mathrm{~m}$ away from the GC analyzer (4890D, Agilent Technologies Inc., China) in the house. The chambers were constructed using stainless steel (frame) and polycarbonate (translucent walls). Each chamber covered an area of $0.81 \mathrm{~m}^{2}(0.9 \mathrm{~m} \times 0.9 \mathrm{~m})$ and had an optional height of $0.45 \mathrm{~m}$ (January 1-June 15) or $0.9 \mathrm{~m}$ (June 16-October 15). The detailed setup of the AC system was reported by Liu et al. (2010). During each hour, one of the four chambers was closed for $38 \mathrm{~min}$ for sampling. Thus, each of the four chambers alternately closed once within every $4 \mathrm{~h}$. During each enclosure, five gas samples were taken from the headspace after the chamber had been closed for 1.8, 10.8, 19.8, 28.8 and $37.8 \mathrm{~min}$. Each sample was immediately analyzed online after being transported through a Teflon tube and injected into the GC. The analysis of each gas sample took 3 min. Pure nitrogen gas $\left(\mathrm{N}_{2}, 99.999 \%\right)$ was used as the carrier. A buffering gas with $10 \% \mathrm{CO}_{2}$ in pure $\mathrm{N}_{2}$ flowed through the ECD cell at a rate of $1-2 \mathrm{~mL} \mathrm{~min}^{-1}$ to eliminate the influence of the sampled $\mathrm{CO}_{2}$ on $\mathrm{N}_{2} \mathrm{O}$ detection (Zheng et al., 2008; Wang et al., 2010). The $\mathrm{N}_{2} \mathrm{O}$ concentrations were calibrated with three reference gas (330 ppbv) injections in each hour. The instrument precision varied between \pm 0.3 and $\pm 3.2 \mathrm{ppbv}$, with a mean of $\pm 1.4 \mathrm{ppbv}$. The detection limits of the hourly fluxes were 1.0-10.8 (mean: 4.6) $\mu \mathrm{g} \mathrm{N} \mathrm{m}^{-2} \mathrm{~h}^{-1}$ for the $45-\mathrm{cm}$ high chambers.

The hourly chamber fluxes were determined by the nonlinear (exponential) or linear method using the $\mathrm{N}_{2} \mathrm{O}$ concentration data during each chamber enclosure. First, several criteria were applied to detect significant nonlinear cases. The criteria were as follows: (a) all the five $\mathrm{N}_{2} \mathrm{O}$ concentration data were valid; (b) the concentration-time relationship could be significantly $(p<0.05)$ fitted with not only the linear function $\left(C=a_{0}+a_{1} t\right.$, where $C$ is the measured concentration, $a_{0}$ is the intercept, $a_{1}$ is the slope of the fitting line, and $t$ is the time), but also the nonlinear (exponential) function following Valente et al. (1995) and Kroon et al. (2008) $\left(C=k_{1} / k_{2}+\left(C_{0}-k_{1} / k_{2}\right) \cdot \exp \left(-k_{2} t\right)\right.$, where $C_{0}$ is the concentration at the beginning of the enclosure, and $k_{1}$ and $k_{2}$ are the fitting parameters); (c) the correlation coefficient of the nonlinear regression was at least 0.001 greater than that of the linear regression; and (d) the initial slope of the nonlinear fitting curve $\left(d C /\left.d t\right|_{t=0}=k_{1}-k_{2} C_{0}\right)$ was larger than the slope of the linear fitting line $\left(d C / d t=a_{1}\right)$. If these criteria were satisfied, the hourly chamber flux was determined based on the initial slope of the nonlinear regression; otherwise, the slope of the linear regression was used to calculate the flux $(p<0.05$ and concentration number $\geq 3)$. The measurements with neither significant nonlinear nor linear relationships between the concentrations and time were regarded as gaps. The daily mean flux was calculated as the arithmetic mean of all of the hourly chamber fluxes on a given day.

The chamber fluxes usually have high variability among spatially replicated locations. To compare the fluxes measured using the two methods, the hourly chamber fluxes were corrected using Eq. (1) to remove their spatial variation.

$f_{i j}^{\prime}=f_{i j} \cdot \frac{\bar{F}}{F_{j}}$

In Eq. (1), $f_{i j}^{\prime}$ is the $i$ th corrected hourly flux at the $j$ th location $(i=1,2, \ldots, 6 ; j=1,2, \ldots, 4), f_{i j}$ is the $i$ th uncorrected hourly flux at the $j$ th location, $F_{j}$ is the daily cumulative emission determined by the fluxes at the $j$ th location, and $\bar{F}$ is the mean value of the daily cumulative fluxes measured at the four locations.

\subsubsection{Manual chamber}

To obtain the full-year $\mathrm{N}_{2} \mathrm{O}$ fluxes, we conducted manual measurements near the $\mathrm{AC}$ locations using four static opaque chambers after the $A C$ measurements were stopped (October 16 to the end of 2009). To calculate the $E F_{\mathrm{d}}$ from the chamber measurements, another four manual chambers were employed to measure the fluxes from four unfertilized subplots $(5 \mathrm{~m} \times 5 \mathrm{~m})$ as replicates. These subplots were set up on January 1, 2009 and located in the northern cotton field, where the local farmer's practice of fertilization was adopted before our experiment. In addition, we took manual measurements on eight subplots $(3 \mathrm{~m} \times 3 \mathrm{~m})$ from April 20 to October 11,2009 , to investigate the spatial variability of the $\mathrm{N}_{2} \mathrm{O}$ emissions. The eight subplots remained bare and unfertilized and were evenly distributed in the northern and southern cotton fields (Fig. 1b). All of the manual measurements were conducted weekly following the method described by Zheng et al. (2008). Each manual chamber covered an area of $0.25 \mathrm{~m}^{2}$ and had a height of 0.5 or $1.0 \mathrm{~m}$ to adapt to the cotton height. During each chamber enclosure, five $50 \mathrm{~mL}$ gas samples were collected manually with polypropylene syringes at intervals of 8-12 min. All of the gas samples were collected between 09:00 and 10:00 local standard time (LST) as suggested by Liu et al. (2010) and analyzed with a GC (HP 5890, Hewlett-Packard Inc., USA) within $8 \mathrm{~h}$ after collection. The flux calculation followed the same procedure as that used for the $\mathrm{AC}$ measurements. The detection limits of the hourly fluxes for the 45-cm high chambers were 1.2-11.8 (mean: 5.2) $\mu \mathrm{g} \mathrm{N} \mathrm{m}^{-2} \mathrm{~h}^{-1}$.

\subsection{Eddy covariance measurements}

The EC measurements were carried out from January 14 to December 5, 2009, using a three-dimensional sonic anemometer (USA-1, METEK GmbH, Germany) and a TDL trace gas analyzer (TGA-100, Campbell Scientific Inc., USA). The EC measurements are missing between August 24 and September 20 due to vacuum degradation of the laser Dewar. The anemometer and the sample inlet were mounted $2 \mathrm{~m}$ above the ground. The sample air was drawn to the TDL analyzer by a vacuum pump (XDS35i, BOC Edwards, UK). The air was first passed through a diffusive drier (PD1000, Perma pure Inc., USA) to remove excess water vapor. The flow rate of the air entering the drier was $17 \mathrm{~L} \mathrm{~min}^{-1}$, from which the sample flow was $14 \mathrm{Lmin}^{-1}$, and the purge flow was $3 \mathrm{~L} \mathrm{~min}^{-1}$. The sample air leaving the dryer was directed to the TDL analyzer via a $10 \mathrm{~m}$ long Teflon tube (i.d.: $4 \mathrm{~mm}$ ). The pressure inside the sample cell was kept at $55 \mathrm{hPa}$ during the measurement period. The wind velocities and $\mathrm{N}_{2} \mathrm{O}$ concentrations were recorded at a frequency of $10 \mathrm{~Hz}$. Following the TGA-100 reference manual (supplied by Campbell Scientific), we performed a "two point" calibration three times using a zero (pure $\mathrm{N}_{2}$ ) and a span gas ( $340 \mathrm{ppbv}$ $\mathrm{N}_{2} \mathrm{O}$ in pure $\mathrm{N}_{2}$ ). One calibration was done before starting the 
measurement (January 13, 2009), and the other two were conducted after technical maintenance on the laser during the measurement period (on June 8 and September 23, 2009).

The EC fluxes were calculated as the average covariance between the vertical wind velocity and the $\mathrm{N}_{2} \mathrm{O}$ concentration over $30 \mathrm{~min}$. Before the flux calculation, spike detection (Vickers and Mahrt, 1997) was applied to the measured variables, and a two-dimensional coordinate rotation (Kaimal and Finnigan, 1994) was performed on the wind components. The lag time due to the residence time of the sample air in the inlet tubing was determined by maximizing the covariance between the vertical wind velocity and the $\mathrm{N}_{2} \mathrm{O}$ concentration. There was a clear lag time of approximately $1 \mathrm{~s}$ during the high-emission period after the fertilization and irrigation. However, it was impossible to define the lag time for each half hour during the other periods. Therefore, a fixed lag-time of $1 \mathrm{~s}$ was used for the correction during the lowemission periods. The vertical wind velocity was de-trended using a linear de-trending (LDT) procedure. According to TGA-100 reference manual, the $\mathrm{N}_{2} \mathrm{O}$ signals measured by the TDL gas analyzer have offset errors caused by optical interference (fringe effects), which in theory change slowly in time. In that case the noises can be easily removed by standard LDT procedure when calculating the EC fluxes. However in our case the offset drift changed faster than the EC averaging time $(30 \mathrm{~min})$. It could give artificial extra contribution to the fluxes when the vertical wind fluctuations correlated with the concentration fluctuations (Mammarella et al., 2010). To remove the offset noises, an autoregressive running mean filter (McMillen, 1988) with a time constant of $50 \mathrm{~s}$ was applied to the $\mathrm{N}_{2} \mathrm{O}$ signals. The time constant was determined based on the Allan variance analysis (Werle et al., 1993). The flux correction for the density fluctuation due to temperature and water vapor (Webb et al., 1980) was unnecessary due to temperature fluctuation damping by the long tube and drying of the sample air prior to the concentration analysis. The fluxes were corrected for the high frequency loss by $15 \%$ on average, which was estimated according to the method described by Horst (1997), assuming similarity between the sensible heat and $\mathrm{N}_{2} \mathrm{O}$ co-spectra.

The stationarity test and the integral turbulence characteristic test (Foken and Wichura, 1996) were applied to the $\mathrm{N}_{2} \mathrm{O}$ fluxes to check the flux quality. According to the scheme proposed by Foken and Wichura (1996), only the fluxes with quality classes of 1-6 were accepted. The footprint model (Horst and Weil, 1994) shows that under near-neutral conditions, the area from which $80 \%$ of the flux was obtained lay within $90 \mathrm{~m}$ and $200 \mathrm{~m}$ of the EC mast during the growing period (cotton height $\sim 1 \mathrm{~m}$ ) and the fallow period (plowed bare soil), respectively. Accordingly, we rejected the fluxes from the direction sectors of $0-30^{\circ}$ and $300-360^{\circ}$ due to the insufficient footprint. However, data from the chamber directions $\left(30-60^{\circ}\right)$ were remained for further analysis.

The detection limit of the EC system $\left(F_{\text {det }}\right)$ was estimated with $F_{\text {det }}=2 \sigma_{w} \cdot 2 \sigma_{c} \cdot(T f)^{-1 / 2}$, where $\sigma_{w}$ is the standard deviation of the vertical wind velocity at the observational level $\left(\mathrm{m} \mathrm{s}^{-1}\right), \sigma_{c}$ is the noise level of the TDL for $\mathrm{N}_{2} \mathrm{O}$ (ppbv), $T$ is the averaging time (s), $f$ is the measurement frequency $(\mathrm{Hz})$, and the factors of 2 were introduced to estimate the detection limit at the 95\% confidential interval (Pihlatie et al., 2005). In this study, $\sigma_{c}$ was estimated as $1.5 \mathrm{ppbv}$, and the mean $\sigma_{w}$ during the measurement period was approximately $0.18 \mathrm{~m} \mathrm{~s}^{-1}$. For an averaging period of $30 \mathrm{~min}$, the detection limit of the $\mathrm{N}_{2} \mathrm{O}$ fluxes was $37.6 \mu \mathrm{g} \mathrm{N} \mathrm{m}^{-2} \mathrm{~h}^{-1}$. For the daily mean values of $\mathrm{N}_{2} \mathrm{O}$ emissions, the detection limit decreased to approximately $5.4 \mu \mathrm{g} \mathrm{N} \mathrm{m} \mathrm{h}^{-2} \mathrm{~h}^{-1}$.

Previous studies demonstrated very large variability in $30-\mathrm{min}$ $\mathrm{N}_{2} \mathrm{O}$ fluxes, especially when the fluxes were close to the instrumental detection limit (Pihlatie et al., 2005, 2010; Mammarella et al., 2010). According to Wilson and Meyers (2001), the large variability within 30-min time scale resulted mostly from statistical random errors due to single measurement point and finite sampling period. However, the long-term ( $\geq 1$ day) variation of the fluxes is less prone to these sampling errors. Accordingly, to reduce the random errors and lower the detection limit, we averaged the 30-min fluxes over a one-day period (flux number $\geq 4$ ).

\subsection{Additional measurements}

A weather station (Changwang Meteorological Technology Co. Ltd., China) was located adjacent to the experimental field to measure the hourly meteorological variables, including the air $(2-\mathrm{m}$ height) and soil (5-cm depth) temperatures, the precipitation and the atmospheric pressure. The global radiation was recorded every half hour to determine the daytime $\left(\geq 10 \mathrm{~W} \mathrm{~m}^{-2}\right)$ and nighttime $\left(<10 \mathrm{~W} \mathrm{~m}^{-2}\right)$ periods. The air and soil (5-cm depth) temperatures inside the chambers were measured every minute with thermocouples. The volumetric moisture of the topsoil $(0-6 \mathrm{~cm})$ was manually measured every day with a portable probe (ML2x, ThetaKit, Delta-T Devices, UK) during the non-frozen period and with the gravimetric method during the frozen period. The volumetric moisture values were converted into water-filled pore space (WFPS) using the bulk density $\left(1.20 \mathrm{~g} \mathrm{~cm}^{-3}\right)$ and a theoretical particle density $\left(2.65 \mathrm{~g} \mathrm{~cm}^{-3}\right)$. The soil nitrate $\left(\mathrm{NO}_{3}{ }^{-}\right)$and ammonium $\left(\mathrm{NH}_{4}{ }^{+}\right)$ contents were measured from April 10 to December 31, 2009. Four soil samples were randomly collected from the top layer $(0-10 \mathrm{~cm})$ near the automatic chambers once every 2-4 days for one month following the fertilizer application and once a week during the other periods. The soil samples were immediately extracted with a $2 \mathrm{M} \mathrm{KCl}$ solution (Keeney and Nelson, 1982). The extracts were frozen at $-18{ }^{\circ} \mathrm{C}$ and analyzed later for $\mathrm{NO}_{3}{ }^{-}$and $\mathrm{NH}_{4}{ }^{+}$concentrations using an automatic nitrogen analyzer $\left(\mathrm{San}^{++}\right.$Continuous Flow Analyzer, Skalar Analytical B.V., The Netherlands).

\subsection{Estimation of cumulative fluxes and direct emission factors}

The cumulative chamber flux over a particular period (e.g., the annual emission) was determined as follows:

$F_{\text {cum }}=10^{-5} \sum_{i=1}^{N} F_{\text {day }_{i}}$

where $F_{\text {cum }}$ is the cumulative flux $\left(\mathrm{kg} \mathrm{Nha}^{-1}\right), N$ is the number of days over this period, and $F_{\mathrm{day}_{i}}$ is the daily flux of the $i$ th day $\left(\mu \mathrm{g} \mathrm{N} \mathrm{m}^{-2} \mathrm{~d}^{-1}\right)$. For a single chamber, a daily flux was calculated by integrating the 24 hourly fluxes of the day, before which the hourly gaps were filled with the averages of the good values of the day. Daily gaps were filled using linear interpolation based on the previous and following good daily values (Mishurov and Kiely, 2011). The final cumulative chamber flux was estimated as the average of the four spatial replicates. The cumulative fluxes of the EC data were calculated in a similar way using Eq. (2). However, the daily fluxes during the low-emission periods were directly determined by multiplying the daily mean flux $\left(\mu \mathrm{g} \mathrm{N} \mathrm{m}^{-2} \mathrm{~h}^{-1}\right)$ by $24 \mathrm{~h}$ due to the large random uncertainties in the 30 -min EC fluxes.

The annual $E F_{\mathrm{d}}(\%)$ of fertilizer nitrogen was calculated as $E F_{\mathrm{d}}=$ $\left(E_{\mathrm{F}}-E_{0}\right) / N_{\mathrm{F}} \cdot 100 \%$, where $N_{\mathrm{F}}$ is the amount of applied fertilizer nitrogen $\left(\mathrm{kg} \mathrm{Nha}^{-1} \mathrm{yr}^{-1}\right), E_{\mathrm{F}}$ is the annual emission under the fertilized condition $\left(\mathrm{kgNha}^{-1} \mathrm{yr}^{-1}\right)$, and $E_{0}$ is the annual emission ( $\mathrm{kg} \mathrm{Nha}^{-1} \mathrm{yr}^{-1}$ ) under unfertilized conditions in the current year (background emission). For the chambers, $E_{0}$ was determined as the mean of the annual fluxes from the four unfertilized subplots. For the EC measurements, $E_{0}$ was estimated based on all of the EC fluxes excluding the fertilizer-induced emission from June 28 to July 29. 


\subsection{Estimation of flux uncertainties}

\subsubsection{Uncertainties in chamber fluxes}

We estimated both the random and systematic uncertainties in the chamber fluxes.

The random uncertainty in an hourly chamber flux $\left(u_{\mathrm{hr}}\right)$ was mainly introduced by the instrumental detection noise, which could be estimated with the GC precision for $\mathrm{N}_{2} \mathrm{O}$ detection $( \pm 1.4 \mathrm{ppbv})$. The random uncertainty in a daily flux $\left(u_{\text {day }}\right)$ was determined using Eq. (3), which includes three terms: the random uncertainty propagated from the hourly fluxes at each chamber location, the spatial variation $\left(u_{\mathrm{sv}}\right)$ among the four chambers $(N=4)$ and the bias in the diurnal variation pattern $\left(u_{\mathrm{dv}}\right)$ when up-scaling the six hourly data points of an individual chamber to a daily flux. The random uncertainty in the annual flux ( $u_{\text {year }}$ ) was determined using Eq. (4), where $\left(u_{\text {day }}\right)_{i}$ denotes the uncertainty in the $i$ th daily flux $(i=1, \ldots, 365), m$ is the number of gap-filled daily fluxes, and $\left(u_{g f}\right)_{j}$ denotes the uncertainty in gap-filling the $j$ th missing daily flux $(j=1, \ldots, m)$. The $u_{\text {day }}$ of each gap-filled daily flux was treated as the mean uncertainty of the data used for gap-filling, and $u_{\mathrm{gf}}$ was determined as twice the standard deviation of the data that were used to fill the gaps.

$u_{\text {day }}=\sqrt{\frac{\left(24 u_{\mathrm{hr}}^{2}+u_{\mathrm{dv}}^{2}\right)}{N}+u_{\mathrm{sv}}^{2}}$

$u_{\text {year }}=\sqrt{\sum_{i=1}^{365}\left[\left(u_{\text {day }}\right)_{i}\right]^{2}+\sum_{j=1}^{m}\left[\left(u_{\mathrm{gf}}\right)_{j}\right]^{2}}$

The chamber fluxes were prone to a number of systematic uncertainties. First, failure to detect significant nonlinearity in the flux calculation could lead to underestimated fluxes. Due to the small number of $\mathrm{N}_{2} \mathrm{O}$ concentration data points $(n=5)$ during each enclosure period, significant nonlinearity could not be detected to a large extent. In that case, the linear method had to be used for flux determination. To estimate this underestimation, we calculated the differences in the fluxes determined by the nonlinear and linear procedures as well as the frequency of the cases in which the nonlinearity requirements were not fulfilled. Then, this error was determined as the product of the two estimated values. Second, the chamber deployment and the use of fans within the chambers might modify the air mass flow between the soil pores and the chamber air, and thus under- or over-estimate the fluxes under different ambient turbulent conditions (Xu et al., 2006; Lai et al., 2012). However, we did not attempt to quantify this error due to a lack of appropriate method. Some other reasons might cause systematic errors, such as the modification of the enclosed environment and the pressure perturbation caused by closing the chamber lids and collecting the air samples through suction. However, these errors were regarded as negligible due to the improvements in the chamber designs and routine system maintenance (Liu et al., 2010, 2011). Therefore, only the first aspect was taken into account when evaluating the systematic uncertainties in our chamber fluxes.

\subsubsection{Uncertainties in eddy covariance fluxes}

Following Kroon et al. (2010), the random uncertainty in a 30-min EC flux was assumed to be dominated by the one-point sampling uncertainty $\left(u_{\mathrm{op}}\right)$. This uncertainty was estimated using Eq. (5).

$u_{\mathrm{op}}=2 \sqrt{\frac{20 z}{T U}} \sqrt{\overline{\left(w^{\prime} c^{\prime}\right)^{2}}-\left(\overline{w^{\prime} c^{\prime}}\right)^{2}}$

In Eq. (5), $z$ is the measurement height ( $\mathrm{m}), T$ is the averaging time (s), $U$ is the mean horizontal wind velocity $\left(\mathrm{m} \mathrm{s}^{-1}\right)$, and $\sqrt{\overline{\left(w^{\prime} c^{\prime}\right)^{2}}-\left(\overline{w^{\prime} c^{\prime}}\right)^{2}}$ represents the standard deviation of the quantity $w^{\prime} c^{\prime}$, where $w^{\prime}$ and $c^{\prime}$ are the instantaneous deviations of the vertical wind velocity $\left(\mathrm{ms}^{-1}\right)$ and the $\mathrm{N}_{2} \mathrm{O}$ concentration (ppbv) from the mean values, respectively. Compared with Eq. (A.4) in Kroon et al. (2010), Eq. (5) has an additional factor of 2, which was introduced to estimate $u_{\text {op }}$ at the $95 \%$ confidence interval. For a daily EC flux, the random uncertainty $\left(u_{\text {day }}\right)$ was evaluated as follows:

$u_{\text {day }}=\sqrt{\sum_{i=1}^{48}\left[\left(u_{\mathrm{op}}\right)_{i}\right]^{2}+\sum_{j=1}^{n}\left[\left(u_{\mathrm{dv}}\right)_{j}\right]^{2}}$

where $\left(u_{\mathrm{op}}\right)_{i}$ is the one-point sampling uncertainty of a given individual 30 -min flux $(i=1, \ldots, 48), n$ is the number of missing $30-$ min fluxes, and $\left(u_{\mathrm{dv}}\right)_{j}$ is the bias in the diurnal variation pattern due to gap-filling the $j$ th missing flux $(j=1, \ldots, n)$. The $u_{\text {op }}$ of each missing flux was treated as the mean random uncertainty of the available 30 -min fluxes of the day. Finally, the random uncertainty in the annual EC flux ( $u_{\text {year }}$ ) was calculated with Eq. (4).

\subsection{Statistical analysis}

In this study, the 95\% confidence interval was used to determine the instrumental detection limits, the statistical significance and the uncertainties in fluxes. The software package SPSS Statistics Client 19.0 (SPSS China, Beijing, China) was used to perform regression analyses and test the significance of differences in the $\mathrm{N}_{2} \mathrm{O}$ fluxes between the two techniques with a one-way ANOVA. The Origin 8.0 software package (Origin Lab Ltd., Guangzhou, China) was used for the graphical outputs.

\section{Results and discussion}

\subsection{Environmental conditions}

The annual mean air temperature of the experimental site in 2009 was $14.6^{\circ} \mathrm{C}$, with a daily maximum of $30.5^{\circ} \mathrm{C}$ in June and a daily minimum of $-9.3^{\circ} \mathrm{C}$ in January. The day-to-day patterns of the daily soil temperature means were similar to those of the air temperature (Fig. 2a). The total precipitation in 2009 was $555.3 \mathrm{~mm}$, $80 \%$ of which fell between May and September. Including the total irrigation of $150.5 \mathrm{~mm}$ (Fig. 2b), the cotton field received $705.8 \mathrm{~mm}$ water throughout the year. The soil water content varied with the rainfall and irrigation events. The average daily soil moisture ranged widely from $15.6 \%$ to $72.3 \%$ (mean: $41.3 \%$ ) in WFPS (Fig. 2b). However, the obtained WFPS might have underestimated the water content in the top soil layer because the measurements were taken only at the uppermost $0-6 \mathrm{~cm}$ depth. The soil $\mathrm{NH}_{4}{ }^{+}$contents ranged from 0.1 to 99.4 (mean: 10.3 ) $\mathrm{mg} \mathrm{N} \mathrm{kg}^{-1}$ soil dry weight (SDW) (Fig. 2c). They remained rather low during the entire experimental period, with the exception of a significant peak immediately after the nitrogen fertilization. The soil $\mathrm{NO}_{3}{ }^{-}$contents varied from 0.2 to 164.2 (mean: 17.9 ) $\mathrm{mg} \mathrm{N} \mathrm{kg}^{-1}$ SDW. Compared with the $\mathrm{NH}_{4}^{+}$ contents, the $\mathrm{NO}_{3}{ }^{-}$contents increased more slowly after the fertilization, and a significant increase only occurred after the following irrigation event (Fig. 2c).

\subsection{Nitrous oxide fluxes from chamber measurements}

\subsubsection{Variation of chamber fluxes}

A total of 3812 valid hourly fluxes were obtained from the AC measurements, leading to data coverage of $56 \%$. Nearly $31 \%$ of the AC data were rejected because a significant concentration-time relationship $(p<0.05)$ was not detected, and the other $13 \%$ was rejected due to instrument failures, daily technical maintenance 

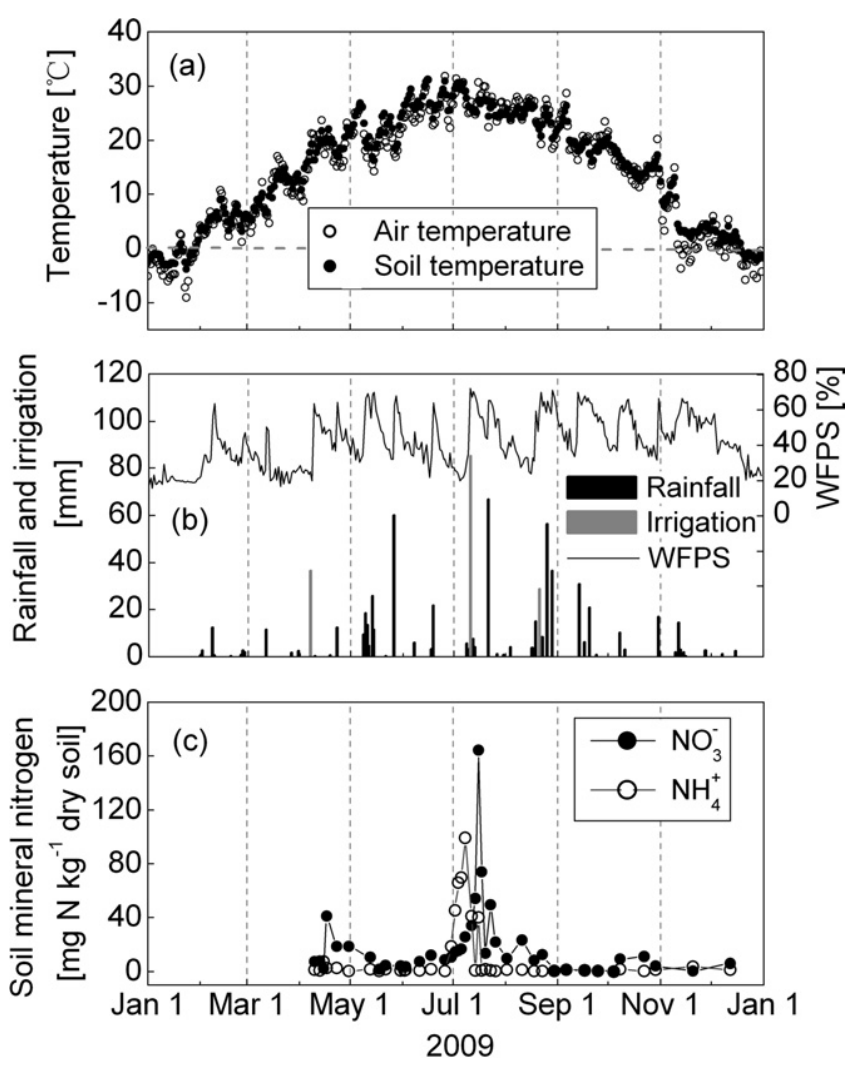

Fig. 2. (a) Daily mean air and soil (5 cm depth) temperatures, (b) the daily precipitation, water amount of the each irrigation event and daily mean soil moisture (WFPS) at depths of $0-6 \mathrm{~cm}$, and (c) the soil ammonium $\left(\mathrm{NH}_{4}^{+}\right)$and nitrate $\left(\mathrm{NO}_{3}{ }^{-}\right)$ concentrations at depths of $0-20 \mathrm{~cm}$.

and power failures. Approximately $46 \%$ of the valid AC fluxes were collected from January 1 to June 15 using the $45-\mathrm{cm}$ high chambers, while the others were obtained from June 16 to October 15 using the $90-\mathrm{cm}$ high chambers. We found $98 \%$ of the AC fluxes were above the lowest detection limit and $72 \%$ above the mean detection limit. The manual measurements provided 221 valid hourly fluxes from October 16 to December 31. During the entire measurement period, the hourly chamber fluxes varied from 0.6 to 781.8 (mean: 26.9) $\mu \mathrm{g} \mathrm{N} \mathrm{m}^{-2} \mathrm{~h}^{-1}$ (Fig. 3a). The fluxes were characterized by a short burst of high emission after the irrigation that followed the nitrogen fertilization and by low-level emission along with several small peaks during the other periods. Although the nitrogen fertilizer was applied on June 28, significantly higher $\mathrm{N}_{2} \mathrm{O}$ fluxes were not observed until July 12 , when the irrigation occurred at the chamber locations.

During the entire experimental period, the mean, median, minimum and maximum values of the daily mean fluxes were 19.7, 8.7, 1.2 and $468.8 \mu \mathrm{g} \mathrm{N} \mathrm{m}^{-2} \mathrm{~h}^{-1}$, respectively (Fig. $3 \mathrm{~b}$ and $\mathrm{c}$ ). The coefficients of variation (CV) of the daily diurnal measurements were averaged to 59\%. According to the flux magnitudes, the fullyear period was divided into three stages, which spanned from January 1 to July 11 , July 12 to July 29 and July 30 to December 31 , respectively. The fluxes of the second stage were 14 times higher $(p<0.01)$ than those of the first and third stages. Therefore, we referred to the second stage as the high-emission period and the other two stages as the low-emission periods.

The daily mean fluxes during the high-emission period peaked on July 14, decreased gradually in the following week, increased again with another less-intensive peak on July 23 due to a rainfall event $(66.7 \mathrm{~mm})$ on the previous day and then declined until the end of this period (Fig. 3c). The fluxes corresponded well with the

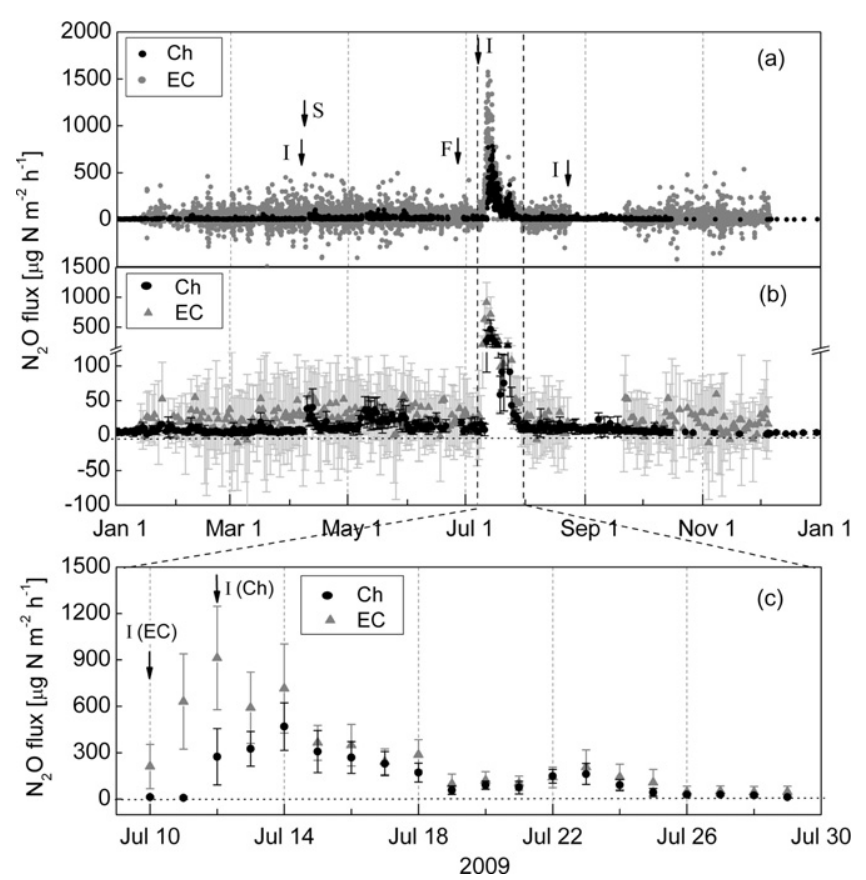

Fig. 3. $\mathrm{N}_{2} \mathrm{O}$ fluxes measured with the static chamber (Ch) and eddy covariance (EC) techniques. Panel (a) shows the instantaneous fluxes (Ch: hourly; EC: 30-min); the arrows with "I", "S" and " $\mathrm{F}$ " indicate the dates of irrigation, sowing and nitrogen fertilization events, respectively. Panels (b) and (c) represent the daily mean fluxes; each error bar stands for the standard deviation of the measurements of each day.

evolutions of the soil moisture contents (Fig. 2b), showing a significant and positive exponential correlation $\left(R^{2}=0.56, p<0.01\right)$. Fig. 4 a shows the hourly AC fluxes during the high-emission period, where the black solid line represents the moving averages with a step length of 4 . It illustrates notable diurnal cycles with lower fluxes during the nighttime and higher fluxes during the daytime, which is consistent with the diurnal variation of the soil (5-cm depth) temperature. The diurnal cycles were even more obvious in the first week of the high-emission period.

However, during the low-emission periods, the $\mathrm{N}_{2} \mathrm{O}$ fluxes did not show clear diurnal cycles. The daily mean fluxes were positive and close to the instrumental detection limits (Fig. 3b) during the fallow season (January 1-April 7). Then, a small peak appeared after the first irrigation on April 8. In mid- to late-May, the fluxes fluctuated to a larger extent due to several rainfall events. From early August to December, the fluxes remained as low as they were in the fallow season, despite the fact that one irrigation and several rainfall events occurred.

We found significant relationships between the daily mean chamber fluxes and the nitrate contents, moisture contents and temperature of the topsoil, which were described using Eq. (7) that follows the Arrhenius kinetics $\left(R^{2}=0.46, p<0.001 ; a=653, b=144\right.$, $\left.E_{\mathrm{a}}=14\right)$. The relationship implies that denitrification dominated the $\mathrm{N}_{2} \mathrm{O}$ emissions. At the same time, the daily mean fluxes also correlated with the soil nitrate contents alone, which was described using Eq. (8) $\left(R^{2}=0.45, p<0.001 ; c=3.75, d=-12.3\right)$. The similar $R^{2}$ values derived from the regressions of Eqs. (7) and (8) suggest that nitrate availability was the most important regulating factor for the denitrification process to produce $\mathrm{N}_{2} \mathrm{O}$.

$F_{\mathrm{dm}}=\left(a\left[\mathrm{NO}_{3}^{-}\right]+b\right.$ WFPS $) e^{-E_{\mathrm{a}} /\left(R T_{k}\right)}$

$F_{d m}=c\left[N O_{3}^{-}\right]+d$

In Eqs. (7) and (8), $F_{\mathrm{dm}}$ is the daily mean $\mathrm{N}_{2} \mathrm{O}$ flux $\left(\mu \mathrm{g} \mathrm{N} \mathrm{m}^{-2} \mathrm{~h}^{-1}\right)$, $\left[\mathrm{NO}_{3}{ }^{-}\right]$is the soil nitrate content $\left(\mathrm{mg} \mathrm{N} \mathrm{kg}^{-1} \mathrm{SDW}\right)$, WFPS is the soil moisture (\%), $T_{k}$ is the soil temperature (K), $R$ is the molar gas 

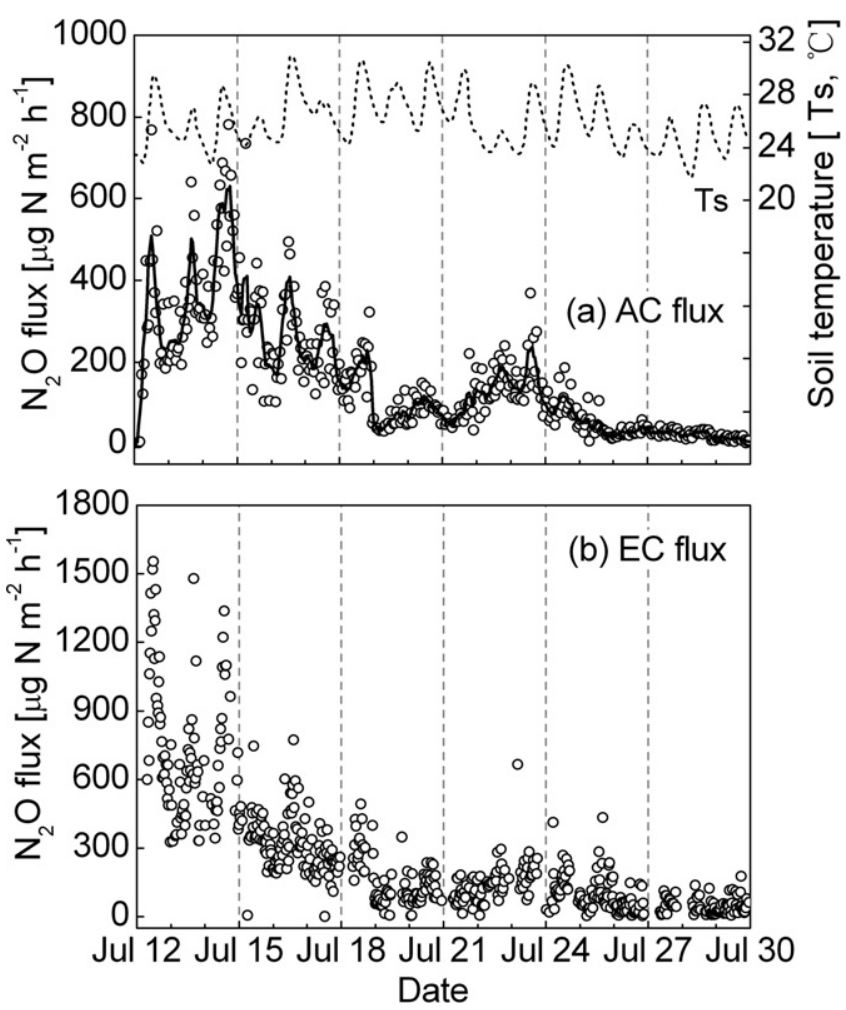

Fig. 4. Hourly $\mathrm{N}_{2} \mathrm{O}$ fluxes measured with the automatic static chambers (AC) and 30-min fluxes measured with the eddy covariance system (EC) during the highemission period. In panel (a), the dashed line represents the hourly soil temperature at a depth of $5 \mathrm{~cm}$, and the black solid line represents the running mean fluxes (step length, $n=4)$.

constant $\left(0.00831 \mathrm{~kJ} \mathrm{~mol}^{-1} \mathrm{~K}^{-1}\right), E_{\mathrm{a}}$ is the apparent activation energy $\left(\mathrm{kJ} \mathrm{mol}^{-1}\right)$, and $a, b, c$ and $d$ are the empirical parameters.

\subsubsection{Uncertainties in chamber fluxes}

The absolute random uncertainties in the hourly chamber fluxes were estimated at \pm 4.6 and $\pm 9.2 \mu \mathrm{g} \mathrm{N} \mathrm{m}^{-2} \mathrm{~h}^{-1}$ for the $45-\mathrm{cm}$ and $90-\mathrm{cm}$ chambers, respectively, which led to relative uncertainties of $\pm 6 \%$ and $\pm 27 \%$ on average during the high- and low-emission periods, respectively. For the daily fluxes $\left(u_{\text {day }}\right)$, the random uncertainties were $\pm 15 \%$ and $\pm 22 \%$ on average during the high- and low-emission periods, respectively. When estimating $u_{\text {day }}$, the diurnal uncertainty $\left(u_{\mathrm{dv}}\right)$ in Eq. ( 3 ) was determined as $\pm 5 \%$ on average during the high-emission period. This value was obtained by comparing the daily fluxes that were extrapolated from the six fluxes of the individual chambers with those calculated from the 24 hourly fluxes from all four of the chambers. However, $u_{\mathrm{dv}}$ could be ignored during the low-emission periods because no significant diurnal patterns were found. The spatial uncertainty $\left(u_{\mathrm{sv}}\right)$ was $37 \%$ and $54 \%$ during the high- and low-emission periods, respectively, which were determined by calculating the spatial CVs of the manual chamber fluxes from the unfertilized, bare-soil subplots. According to Eq. (4), the random uncertainty in the annual chamber flux was estimated at $\pm 8 \%$.

As described in Section 2.6.1, the major systematic uncertainty in the chamber flux was due to failure to detect nonlinearity in the flux calculation. During the entire measurement period, $18 \%$ of the valid hourly fluxes were determined by significant nonlinearity, while the remaining $82 \%$ by significant linearity. This result indicates that at most $82 \%$ of the fluxes might have been underestimated. If the $18 \%$ nonlinear cases were calculated with the linear method, the hourly fluxes would be underestimated by $30 \%$ on average. As a result, our chamber fluxes were likely underestimated by $0-25 \%$, corresponding to the possibility that $0-82 \%$ of the cases was incorrectly treated as linear. Furthermore, if all the cases had been calculated with the linear method, the magnitude of the flux underestimation would be enlarged to $0-30 \%$.

The total chamber flux uncertainties were calculated by adding the random and systematic uncertainties. During the highemission period, the total uncertainties were $-31 \%$ to $6 \%$ for the hourly fluxes and $-40 \%$ to $15 \%$ for the daily fluxes. During the lowemission periods, the total uncertainties in the hourly and daily fluxes were $-52 \%$ to $27 \%$ and $-47 \%$ to $22 \%$, respectively. For the annual flux, the total uncertainty was estimated at $-33 \%$ to $8 \%$, with a median value of $-13 \%$.

\subsection{Nitrous oxide fluxes from eddy covariance measurements}

\subsubsection{Variation of eddy covariance fluxes}

The final data coverage of the EC measurements was $42 \%$. The data gaps were mainly caused by instrument failures, system maintenance and rejection during quality control. The 30-min EC fluxes showed extremely high variability (Fig. 3a), indicated by an average daily CV of 359\%. The 30-min fluxes were accompanied by large random errors during most of the experimental period. The mean, median, minimum and maximum values of the daily mean EC fluxes were $39.8,23.7,-10.8$ and $912.0 \mu \mathrm{g} \mathrm{N} \mathrm{m}^{-2} \mathrm{~h}^{-1}$, respectively, during the entire experimental period (Fig. 3b and c). We also found significant relationships between the daily mean EC fluxes and the studied environmental factors, which could be fitted using Eq. (7) $\left(R^{2}=0.35, p<0.001 ; a=44840, b=1554, E_{\mathrm{a}}=22\right)$ and Eq. ( 8$)\left(R^{2}=0.33, p<0.001 ; c=6.78, d=-21.16\right)$. Compared with the regression parameters of the chambers, the higher $E_{\mathrm{a}}$ of EC was due to the larger fluxes, and the lower $R^{2}$ values were likely because the measurements of the environmental factors were conducted near the chambers and thus did not accurately represent the levels of the major flux source area.

The definitions of the high- and low-emission periods were also adopted for the EC measurements. However, the high-emission period of the EC measurements (July 10-July 29) started 2 days earlier than that of the chambers, due to the unsimultaneous irrigation.

During the high-emission period, the daily mean $\mathrm{N}_{2} \mathrm{O}$ fluxes increased rapidly on July 10 , peaked on July 12 and then gradually declined until the end of this period, with the exception of another peak on July 23 after a rainfall event. During this period, approximately $89 \%$ of the 30 -min fluxes were greater than the detection limit. All of the 30-min fluxes were positive and displayed clear diurnal cycles, although a large portion of the nighttime data was omitted due to weak turbulence (Fig. 4b). The irrigation started from the southern border at 20:00 (LST) on July 9 and ended at the northern border at 04:00 (LST) on July 12 (Fig. 5). Because the irrigation was not simultaneous over the whole field during this period, flux differences among the different wind sectors could reflect the changing wind direction. When the sprinkler was located south of the EC instrument, larger fluxes were basically consistent with wind from the southern sectors $\left(90-270^{\circ}\right)$. However, after the sprinkler was moved to the north of the EC system, this feature tended to disappear (Fig. 5).

During the low-emission periods, the 30 -min fluxes fluctuated greatly. The standard deviations of the diurnal measurements were usually much larger than the magnitudes of the corresponding daily mean fluxes (Fig. 3b). This is because the actual 30-min EC fluxes were near the detection limit. A large portion of the variation was probably resulted from the random errors in addition to the statistical sampling uncertainties (Wilson and Meyers, 2001). To reduce the random errors and get more accurate estimates of the low emissions, we averaged the 30 -min fluxes over a 1-day period. This procedure allowed the comparison between the daily mean EC and chamber fluxes during the low-emission periods. As a result, 


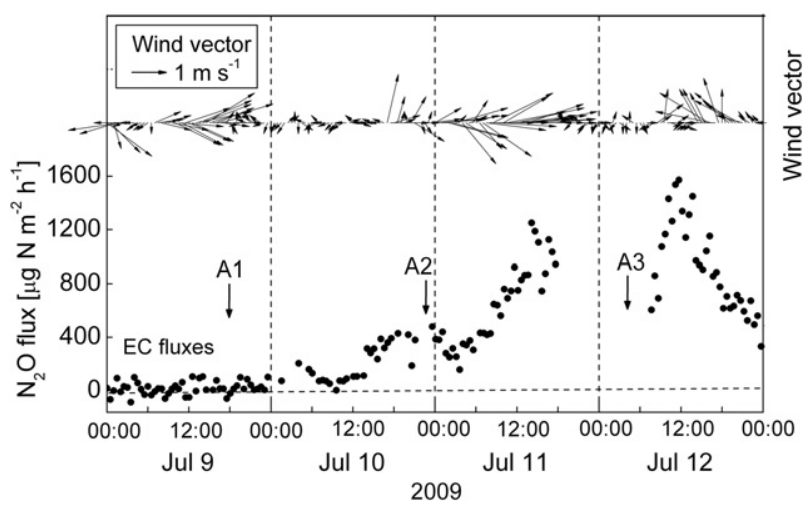

Fig. 5. The 30-min averaged wind vector and $\mathrm{N}_{2} \mathrm{O}$ fluxes obtained from the eddy covariance (EC) measurements during the irrigation event from July 9 to $12,2009$. The arrows representing the wind vector are directed according to the wind direction, and their lengths are proportional to the wind speeds. The arrows A1 and A3 indicate the time of the beginning and ending of the irrigation, respectively, and A2 shows the time when the sprinkler was moved to the north of the EC instruments.

approximately $90 \%$ of the daily mean flux values during the lowemission periods were positive, and were all above the detection limit for the daily mean fluxes $\left(5.4 \mu \mathrm{g} \mathrm{N} \mathrm{m}^{-2} \mathrm{~h}^{-1}\right)$.

We sorted the $30-$ min EC fluxes by twelve wind sectors $\left(30^{\circ}\right.$ for each) to examine the emissions in the different directions from the EC mast. Fig. 6 illustrated the averaged $\mathrm{N}_{2} \mathrm{O}$ fluxes over each wind sector during the high- and low-emission periods. Although the results of the $0-30^{\circ}$ and $300-360^{\circ}$ direction sectors were given
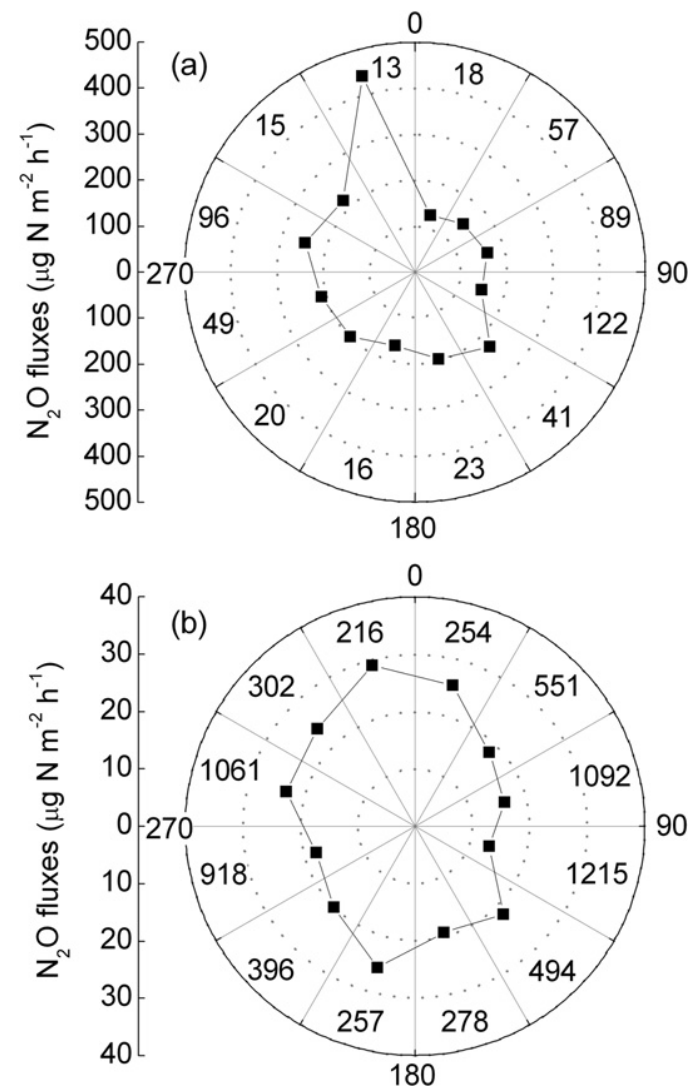

Fig. 6. $\mathrm{N}_{2} \mathrm{O}$ fluxes from different wind directions measured with the eddy covariance technique during (a) the high-emission period (July 13-29) and (b) the low-emission periods (January 1-July 9 and July 30-December 5). The squares represent the mean fluxes of each $30^{\circ}$-sector. Zero degree represents the geographical north direction. The figures shown in each wind sector indicate the number of 30-min fluxes obtained from the corresponding sector. in the figure, they were omitted in the statistics shown below. During the high-emission period, the sector-averaged fluxes varied from 148.0 to $247.5 \mu \mathrm{g} \mathrm{N} \mathrm{m}^{-2} \mathrm{~h}^{-1}$ (Fig. 6a). The minimum flux was from the chamber direction $\left(30-60^{\circ}\right)$, which was approximately $20 \%$ lower than the average flux from all directions. During the low-emission periods, the sector-averaged fluxes ranged from 13.3 to $25.5 \mu \mathrm{g} \mathrm{N} \mathrm{m}{ }^{-2} \mathrm{~h}^{-1}$ (Fig. 6b), and no significant differences were found among the different wind sectors.

\subsubsection{Uncertainties in eddy covariance fluxes}

According to Eq. (5), the random uncertainties in the $30-\mathrm{min}$ EC fluxes were estimated at \pm 676 and $\pm 561 \mu \mathrm{g} \mathrm{N} \mathrm{m}^{-2} \mathrm{~h}^{-1}$, corresponding to relative uncertainties of $\pm 253 \%$ and $\pm 2597 \%$ during the high- and low-emission periods, respectively. However, if we had applied the method introduced by Mammarella et al. (2010), in which the parameterization of the integral time scale $\left(\sigma_{\varphi}\right)$ differs by a factor of 10 , the random uncertainty would decrease by approximately 3 times. We finally used the results estimated from Kroon's method, in which $\sigma_{\varphi}$ is determined with simple surface layer parameterization. When using Eq. (6) to estimate the random uncertainty in a daily EC flux $\left(u_{\text {day }}\right), u_{\mathrm{dv}}$ was assumed to be twice the standard deviation of the daily measurements (76\%) with $100 \%$ data coverage during the high-emission period but could be ignored during the low-emission periods. Consequently, $u_{\text {day }}$ values were estimated at \pm 2433 and $\pm 1916 \mu \mathrm{g} \mathrm{N} \mathrm{m}^{-2} \mathrm{~d}^{-1}$, corresponding to a relative uncertainty of $\pm 47 \%$ and $\pm 366 \%$ during the high- and low-emission periods, respectively. Using Eq. (4), the absolute and relative random uncertainties in the annual EC flux were estimated at $\pm 0.36 \mathrm{~kg} \mathrm{Nha}^{-1} \mathrm{yr}^{-1}$ and $\pm 11 \%$, respectively.

The systematic uncertainty due to an inadequate footprint in the chamber direction sector (30-60 $)$ should be discussed. According to the footprint analysis, during the crucial high-emission period, the cotton area in that wind sector contributed more than $80 \%$ to the EC fluxes, which could well represent the emission level of the cotton field. During the other periods, especially the fallow period, more of the flux might have been contributed by the neighboring field. However, the wind from the chamber direction sector was not as frequent as those from the other sectors (Fig. 1a). The influence was small because we only compared the fluxes with the daily mean values during these periods. Therefore, the footprint uncertainty in our study could be ignored. Another possible systematic error in the EC fluxes was due to the use of RMF. The $\mathrm{N}_{2} \mathrm{O}$ series were filtered using the RMF with a time constant of $50 \mathrm{~s}$. However, this procedure may underestimate the true flux by filtering the contribution of large eddies (Jonker et al., 1999). We compared the fluxes during the high-emission period using LDT and RMF. The results showed a small difference $(<5 \%)$, suggesting that the effect of RMF was negligible. However, such a test was difficult to apply during the low-emission periods because the instrumental noises dominated the value of the covariance function at the assumed true lag time.

\subsection{Comparison between chamber and eddy covariance techniques}

\subsubsection{Instantaneous nitrous oxide fluxes}

When comparing the $\mathrm{N}_{2} \mathrm{O}$ fluxes during the high-emission period, we excluded the data from July 10 to 12 because the EC fluxes of those days were significantly higher $(p<0.01)$ than those of the chambers (Fig. $3 c$ ) due to unsimultaneous irrigation. Fig. 7 shows a significant correlation $\left(R^{2}=0.91, p<0.01\right)$ between the hourly AC fluxes (corrected with Eq. (1)) and the simultaneously measured EC fluxes from the chamber direction sector $\left(30-60^{\circ}\right)$. The linear regression shows that the EC fluxes were $21 \%$ higher. Conversely, it means the AC fluxes were $17 \%$ lower than the EC 


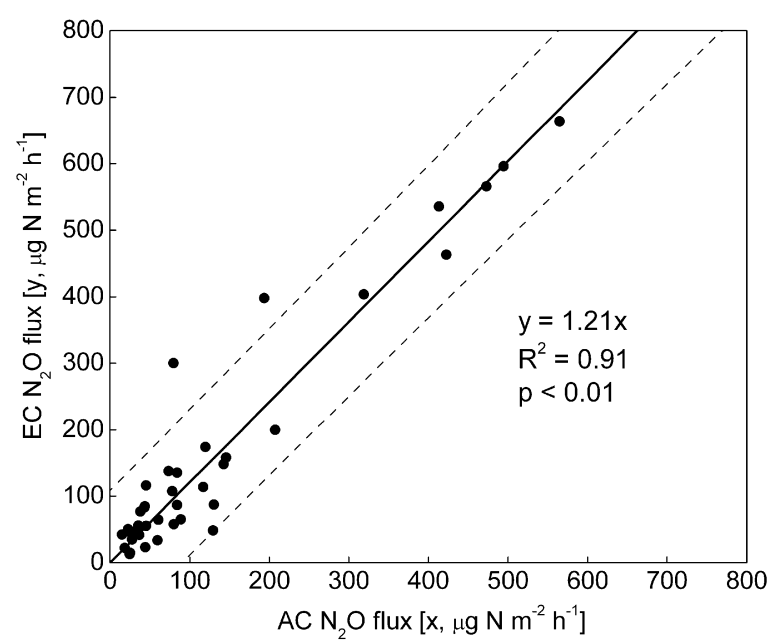

Fig. 7. Comparison between the hourly $\mathrm{N}_{2} \mathrm{O}$ fluxes measured using the automatic chamber (AC) and eddy covariance (EC) technique during the high-emission period (July 13-July 29). The hourly AC fluxes corrected with Eq. (1) and the simultaneous EC fluxes from the chamber direction sector $\left(30-60^{\circ}\right)$ were used for this analysis. The solid line represents the linear and zero-intercept regression of the EC fluxes against the AC fluxes. The dashed lines show the 95\% confidence intervals for the predictions.

fluxes. If we had performed the comparison using the AC fluxes entirely determined by the linear method, the AC fluxes would be $20 \%$ lower than the EC fluxes. Clearly, both estimates fall in the range of the systematic underestimation in the chamber measurements (see Section 3.2.2). This may implicate that the systematic errors of the chamber fluxes were $-17 \%$ to $-20 \%$. We further compared the AC fluxes with the EC fluxes from all wind direction sectors, showing that the EC fluxes were $43 \%$ higher $(p<0.01)$. Compared with the result shown in Fig. 7 , the $22 \%$ larger difference was attributed to the spatial variability among the different wind sectors (Fig. 6a).

During the low-emission periods, all the hourly chamber fluxes were positive, whereas nearly $30 \%$ of the 30 -min EC fluxes were negative. The diurnal chamber and EC fluxes had average daily CVs of $60 \%$ and $386 \%$, respectively. Because the $30-\mathrm{min}$ EC fluxes had very large random errors, directly comparing the high-frequency fluxes was meaningless. Instead, we compared the daily mean values of the chamber and EC fluxes during the lowemission periods, showing that the EC fluxes were $115 \%$ higher $(p<0.01)$.

\subsubsection{Cumulative nitrous oxide fluxes}

The annual emissions for the fertilized condition were estimated at 1.43 and $3.15 \mathrm{~kg} \mathrm{~N} \mathrm{ha}^{-1} \mathrm{yr}^{-1}$ from the chamber and EC measurements, respectively, of which $48 \%$ and $41 \%$ were contributed by the high-emission period. If the data of the period (July 10-12) with unsimultaneous irrigation were excluded, the cumulative emission determined by the EC data during the high emission period was $44 \%$ higher than that of the chambers. As stated in Section 3.4 .1 , nearly half $(22 \%)$ of the difference could be attributed to spatial variability. The remaining difference might have been mainly induced by the negative systematic bias (0-25\%) in the chamber measurements. During the low-emission periods, the cumulative fluxes from the chamber and EC measurements were estimated at 0.75 and $1.85 \mathrm{~kg} \mathrm{~N} \mathrm{ha}^{-1}$, respectively, showing that the EC estimate was $147 \%$ higher. Assuming that the difference in the cumulative fluxes during the high-emission period (44\%) also applies for the low-emission periods, a large portion of the difference (nearly $100 \%$ ) still could not be explained. This is a hint that the EC fluxes might have been biased by other systematic errors that were not recognized. However, concrete experimental evidences were missing to test this assumption.

The annual background emission was estimated at $0.65 \mathrm{~kg} \mathrm{~N} \mathrm{ha}^{-1} \mathrm{yr}^{-1}$ using the chamber data and $1.91 \mathrm{~kg} \mathrm{~N} \mathrm{ha}^{-1} \mathrm{yr}^{-1}$ using the EC data.

\subsubsection{Direct emission factors}

Using the cumulative fluxes from the chamber and EC measurements, the annual $E F_{\mathrm{d}} \mathrm{S}$ were estimated at $1.04 \%$ and $1.65 \%$, respectively. The former estimate falls in the range of $0.22-1.53 \%$ reported for a number of fertilized uplands in China (Zheng et al., 2004), while the latter is slightly higher than the upper limit of that range. The chamber-based estimate of $E F_{\mathrm{d}}$ is lower but approximates the IPCC (2006) default of $1.0 \%$, which is given as the mean of the $E F_{\mathrm{d}}$ s values from global-wide static chamber measurements. Nevertheless, both of the $E F_{\mathrm{d}} \mathrm{s}$ fall in the uncertain range of $0.25-2.25 \%$ for the global fertilized lands (IPCC, 2006). The $E F_{\mathrm{d}}$ from our chamber measurements is also slightly larger than that $(0.95 \%)$ of the same cotton field in the previous year (Liu et al., 2010) and that $(0.80 \%)$ of the neighboring wheat-maize rotation field in the same year (Liu et al., 2011), which were both obtained using the same AC system. The differences may be attributed to the interannual climate variation and different management practices. The relatively high $E F_{\mathrm{d}} \mathrm{S}$ of this study are likely because the processes for $\mathrm{N}_{2} \mathrm{O}$ production were dominated by denitrification. This explanation could be supported by the fitting results of Eqs. (7) and (8) as well as the previous report (Bremner and Blackmer, 1978) that showed the $E F_{\mathrm{d}} \mathrm{S}$ of $\mathrm{N}_{2} \mathrm{O}$ arising from nitrification range from $0.04 \%$ to $0.45 \%$ under fully aerobic conditions.

The $E F_{\mathrm{d}} \mathrm{s}$ from the chamber and EC measurements differed from each other by $-37 \%$ and $59 \%$, respectively. However, the discrepancy is likely specific for the current case, and may vary greatly with changing environmental conditions and management practices. Therefore additional studies are still required to further assess the differences in $E F_{\mathrm{d}} \mathrm{s}$ between the two measurement techniques.

\section{Conclusions}

The static chamber technique based on GC analysis was found to be very robust in detecting $\mathrm{N}_{2} \mathrm{O}$ fluxes from the cotton field throughout the year. The emissions during the 1 -year period were characterized by short duration of much higher fluxes stimulated by the irrigation and rainfall following the nitrogen fertilizer application and long duration of lower emissions during other periods. During the entire experimental period, $72 \%$ of the hourly chamber fluxes were higher than the detection limit of the chamber system. The TDL-based EC technique performed very well during the high-emission period, when most of the 30-min fluxes were above the instrumental detection limit. However, its application for measuring low emissions was still quite uncertain. A reliable comparison between the two techniques was confined to the high-emission period, during which the chamber fluxes were 17-20\% lower than the EC fluxes. This difference may implicate the magnitude of systematic underestimation in the fluxes from chamber measurements. The production of $\mathrm{N}_{2} \mathrm{O}$ in this case was dominated by denitrification, and thus resulted in a higher annual $E F_{\mathrm{d}}$ of $1.04 \%$ from the chamber measurements compared with the cases that were dominated by nitrification processes. The simultaneously measured EC fluxes yielded an annual $E F_{\mathrm{d}}$ of $1.65 \%$, which was significantly larger than the chamber-based estimate. However, the difference in $E F_{\mathrm{d}} \mathrm{s}$ between the two techniques may vary greatly with changing environmental conditions and management practices. Further comparison studies are still needed to elucidate this issue. 


\section{Acknowledgements}

This study was supported by the funding from the Chinese Academy of Sciences (XDA05020100, GJHZ1213 and YZ200909), the National Natural Science Foundation of China (41021004) and the Academy of Finland (projects 124094, 256082, 1127756 postdoctoral project, 137352 and 141518 ICOS, 1118615 Finnish Centre of Excellence, EU projects ICOS, GHG-Europe and InGOS). We also appreciate Guangren Liu, Yinghong Wang, Tingyu Wang, Bingwen Hao, Shixie Meng and Stefan Metzger for their technical support and help with the field measurements.

\section{References}

Ambus, P., Christensen, S., 1994. Measurement of $\mathrm{N}_{2} \mathrm{O}$ emission from a fertilized grassland: an analysis of spatial variability. J. Geophys. Res. 99 (D8), 16549-16555.

Bremner, J.M., Blackmer, A.M., 1978. Nitrous oxide: emission from soils during nitrification of fertilizer nitrogen. Science 199, 295-296.

Butterbach-Bahl, K., Gasche, R., Breuer, L., Papen, H., 1997. Fluxes of NO and $\mathrm{N}_{2} \mathrm{O}$ from temperate forest soils: impact of forest type, $\mathrm{N}$ deposition and of liming on the $\mathrm{NO}$ and $\mathrm{N}_{2} \mathrm{O}$ emissions. Nutr. Cycl. Agroecosyst. 48, 79-90.

Christensen, S., Ambus, P., Arah, J.R., Clayton, H., Galle, B., Griffith, D.W.T., Hargreaves, K.J., Klemedtsson, L., Lind, A.M., Maag, M., Scott, A., Skiba, U., Smith, K.A., Welling, M., Wienhold, F.G., 1996. Nitrous oxide emissions from an agricultural field: comparison between measurements by flux chamber and micrometeorological techniques. Atmos. Environ. 30 (24), 4183-4190.

Crutzen, P.J., Mosier, A.R., Smith, K.A., Winiwarter, W., 2008. $\mathrm{N}_{2} \mathrm{O}$ release from agrobiofuel production negates global warming reduction by replacing fossil fuels. Atmos. Chem. Phys. 8, 389-395.

Davidson, E.A., Savage, K., Verchot, L.V., Navarro, R., 2002. Minimizing artifacts and biases in chamber-based measurements of soil respiration. Agric. For. Meteorol. 113, 21-37.

Desjardins, R.L., Pattey, E., Smith, W.N., Worth, D., Grant, B., Srinivasan, R., MacPherson, J.I., Mauder, M., 2010. Multiscale estimates of $\mathrm{N}_{2} \mathrm{O}$ emissions from agricultural lands. Agric. For. Meteorol. 150, 817-824.

Edwards, G.C. Thurtell, G.W. Kidd, G.E., Dias, G.M., Wagner-Riddle, C., 2003. A diode laser based gas monitor suitable for measurement of trace gas exchange using micrometeorological technique. Agric. For. Meteorol. 115, 71-89.

Eugster, W., Zeyer, K., Zeeman, M., Michna, P., Zingg, A., Buchmann, N., Emmenegger, L., 2007. Methodical study of nitrous oxide eddy covariance measurements using quantum cascade laser spectrometry over a Swiss forest. Biogeosciences 4, 927-939.

Foken, T., Wichura, B., 1996. Tools for quality assessment of surface-based flux measurements. Agric. For. Meteorol. 78, 83-105.

Foken, T., Göckede, M., Mauder, M., Mahrt, L., Amiro, B.D., Munger, J.W., 2003. Postfield Data Quality Control. In: Lee, X. (Ed.), Handbook of Micrometeorology: A Guide for Surface Flux Measurements. Kluwer, Dordrecht, pp. 81-108.

Gong, Z.T., Zhang, G.L., Chen, Z.C., 2007. Pedogenesis and Soil Taxonomy, Chapter 16: Fundamental Properties of Soil Orders and Chapter 21: Reference of Chinese Genetic Soil Classification with Chinese Soil Taxonomy. Science Press, Beijing, China, pp. 359-363, 475-489.

Horst, T.W., Weil, J.C., 1994. How Far Is Far Enough? The fetch requirements for micrometeorological measurement of surface fluxes. J. Atmos. Ocean. Technol. 11, 1018-1025.

Horst, T.W., 1997. A simple formula for attenuation of eddy fluxes measured with first-order-response scalar sensors. Boundary-Layer Meteorol. 82, 219-233.

IPCC, 1997. Revised 1996 IPCC Guidelines for National Greenhouse Gas Inventories: Greenhouse Gas Inventory Reference Manual. IPCC/OECD/IGES, Bracknell.

IPCC, 2006. IPCC Guidelines for National Greenhouse Gas Inventories. Hayama, Japan.

IPCC, 2007. Climate Change 2007: The Physical Science Basis. Contribution of Working Group I to the Fourth Assessment Report of the Intergovernmental Panel on Climate Change. Cambridge University Press, Cambridge, UK.

IUSS (International Union of Soil Sciences) Working Group WRB, 2006. World Reference Base for Soil Resources 2006, 2nd ed. World Soil Resources Reports No. 103, FAO, Rome, Italy, pp. 86-87.

Jonker, H.J.J., Duynkerke, P.G., Cuijpers, J.W.M., 1999. Mesoscales fluctuations in scalars generated by boundary layer convection. J. Atmos. Sci. 56, 801-808.

Jones, S.K., Famulari, D., Di Marco, C.F., Nemitz, E., Skiba, U.M., Rees, R.M., Sutton, M.A., 2011. Nitrous oxide emissions from managed grassland: a comparison of eddy covariance and static chamber measurements. Atmos. Meas. Technol. 4, 2179-2194

Kaimal, J.C., Finnigan, J.J., 1994. Atmospheric Boundary Layer Flows: Their Structure and Measurement. Oxford University Press, New York, Oxford, p. 289.

Keeney, D.R., Nelson, D.W., 1982. Nitrogen-inorganic forms. In: Page, A.L., Miller, R.H., Keeney, D.R. (Eds.), Methods of Soil Analysis: Part 2 Chemical and Microbiological Properties., 2nd ed. Agronomy, Madison, pp. 643-698.

Kroon, P.S., Hensen, A., van den Bulk, W.C.M., Jongejan, P.A.C., Vermeulen, A.T., 2008. The importance of reducing the systematic error due to non-linearity in $\mathrm{N}_{2} \mathrm{O}$ flux measurements by static chambers. Nutr. Cycl. Agroecosyst. 82, 175-186.
Kroon, P.S., Hensen, A., Jonker, H.J.J., Ouwersloot, H.G., Vermeulen, A.T., Bosveld, F.C. 2010. Uncertainties in eddy covariance flux measurements assessed from $\mathrm{CH}_{4}$ and $\mathrm{N}_{2} \mathrm{O}$ observations. Agric. For. Meteorol. 150, 806-816.

Kutzbach, L., Schneider, J., Sachs, T., Giebels, M., Nykänen, H., Shurpali, N.J. Martikainen, P.J., Alm, J., Wilmking, M., 2007. $\mathrm{CO}_{2}$ flux determination by closedchamber methods can be seriously biased by inappropriate application of linear regression. Biogeosciences 4, 1005-1025.

Lai, D.Y.F., Roulet, N.T., Humphreys, E.R., Moore, T.R., Dalva, M., 2012. The effect of atmospheric turbulence and chamber deployment period on autochamber $\mathrm{CO}_{2}$ and $\mathrm{CH}_{4}$ flux measurements in an ombrotrophic peatland. Biogeosciences 9 3305-3322.

Laville, P., Jambert, C., Cellier, P., Delmas, R., 1999. Nitrous oxide fluxes from a fertilized maize crop using micrometeorological and chamber methods. Agric. For. Meteorol. 96, 19-38.

Levy, P.E., Gray, A., Leeson, S.R., Gaiawyn, J., Kelly, M.P.C., Cooper, M.D.A. Dinsmore, K.J., Sheppard, L.J., 2011. Quantification of uncertainty in trace gas fluxes measured by the static chamber method. Eur. J. Soil Sci. 62, 811-821.

Liu, C.Y., Zheng, X.H., Zhou, Z.X., Han, S.H., Wang, Y.H., Wang, K., Liang, W.G., Li, M. Chen, D.L., Yang, Z.P., 2010. Nitrous oxide and nitric oxide emissions from an irrigated cotton field in Northern China. Plant Soil 332, 132-134.

Liu, C.Y., Wang, K., Meng, S.X., Zheng, X.H., Zhou, Z.X., Han, S.H., Chen, D.L., Yang, Z.P., 2011. Effects of irrigation, fertilization and crop straw management on nitrous oxide and nitric oxide emissions from a wheat-maize rotation field in northern China. Agric. Ecosyst. Environ. 140, 226-233.

Livingston, G.P., Hutchinson, G.L., 1995. Enclosure-based measurement of trace gas exchange: application and sources of error. In: Matson, P.A., Harriss, R.C. (Eds.), Biogenic Trace Gases: Measuring Emissions from Soil and Water. Backwell Science, Cambridge, pp. 14-50.

Mammarella, I., Werle, P., Pihlatie, M., Eugster, W., Haapanala, S., Kiese, R., Markkanen, T., Rannik, Ü., Vesala, T., 2010. A case study of eddy covariance flux of $\mathrm{N}_{2} \mathrm{O}$ measured within forest ecosystems: quality control and flux error analysis. Biogeosciences 7, 427-440.

McMillen, R.T., 1988. An eddy correlation technique with extended applicability to non-simple terrain. Boundary-Layer Meteorol. 43, 231-245.

Mishurov, M., Kiely, G., 2011. Gap-filling techniques for the annual sums of nitrous oxide fluxes. Agric. For. Meteorol. 151, 1763-1767.

Neftel, A., Flechard, C., Ammann, C., Conen, F., Emmenegger, L., Zeyer, K., 2007. Experimental assessment of $\mathrm{N}_{2} \mathrm{O}$ background fluxes in grassland systems. Tellus 59B, 470-482.

Neftel, A., Ammann, C., Fischer, C., Spirig, C., Conen, F., Emmenegger, L., Tuzson, B., Wahlen, S., 2010. $\mathrm{N}_{2} \mathrm{O}$ exchange over managed grassland: application of a quantum cascade laser spectrometer for micrometeorological flux measurements. Agric. For. Meteorol. 150, 775-785.

Pihlatie, M., Rinne, J., Ambus, P., Pilegaard, K., Dorsey, J.R., Rannik, Ü., Markkanen, T., Launiainen, S., Vesala, T., 2005. Nitrous oxide emissions from a beech forest floor measured by eddy covariance and soil enclosure techniques. Biogeosciences 2 377-387.

Pihlatie, M., Kiese, R., Brüggemann, N., Butterbach-Bahl, K., Kieloaho, A.-J., Laurila, T., Lohila, A., Mammarella, I., Minkkinen, K., Penttilä, T., Schönborn, J., Vesala, T., 2010. Greenhouse gas fluxes in a drained peatland forest during spring frost-thaw event. Biogeosciences 7, 1715-1727.

Ravishankara, A.R., Daniel, J.S., Portmann, R.W., 2009. Nitrous oxide $\left(\mathrm{N}_{2} \mathrm{O}\right)$ : the dominant ozone-depleting substance emitted in the 21 st Century. Science 326 123-125

Rochette, P., Eriksen-Hamel, N.S., 2008. Chamber measurements of soil nitrous oxide flux: are absolute values reliable? Soil Sci. Soc. Am. J. 72, 331-342.

Smith, K.A., Clayton, H., Arah, J.R.M., Christensen, S., Ambus, P., Fowler, D., Hargreaves, K.J., Skiba, U., Harris, G.W., Wienhold, F.G., Klemedtsson, L., Galle, B., 1994 Micrometeorological and chamber methods for measurement of nitrous oxide fluxes between soils and the atmosphere: overview and conclusion. J. Geophys. Res. 99 (D8), 16541-16548.

Smith, K.A., Dobbie, K.E., 2001. The impact of sampling frequency and sampling times on chamber-based measurements of $\mathrm{N}_{2} \mathrm{O}$ emissions from fertilized soils. Global Change Biol. 57, 933-945.

Stehfest, E., Bouwman, L., 2006. $\mathrm{N}_{2} \mathrm{O}$ and NO emission from agricultural fields and soils under natural vegetation: summarizing available measurement data and modeling of global annual emissions. Nutr. Cycl. Agroecosyst. 74, 207-228.

Valente, R.J., Thornton, F.C., Williams, E.J., 1995. Field comparison of static and flowthrough chamber techniques for measurement of soil NO emission. J. Geophys. Res. 100 (D10), 21147-21152.

Venterea, R.T., Spokas, K.A., Baker, J.M., 2009. Accuracy and precision analysis of chamber-based nitrous oxide gas flux estimates. Soil Sci. Soc. Am. J. 73, 1087-1093.

Vickers, D., Mahrt, L., 1997. Quality control and flux sampling problems for tower and aircraft data. J. Atmos. Ocean. Technol. 14, 512-526.

Wang, Y.H., Wang, Y.S., Ling, H., 2010. A new carrier gas type for accurate measurement of $\mathrm{N}_{2} \mathrm{O}$ by GC-ECD. Adv. Atmos. Sci. 27, 1322-1330.

Webb, E.K., Pearman, G.I., Leuning, R., 1980. Correction of flux measurements for density effects due to heat and water vapor transfer. Quart. J. R. Meteorol. Soc $106,85-100$.

Werle, P., Muecke, R., Slemr, F., 1993. The limits of signal averaging in atmospheric trace gas monitoring by tunable diode-laser absorption spectroscopy. Appl. Phys. B 57, 131-139.

Wilczak, J.M., Oncley, S.P., Sage, S.A., 2001. Sonic anemometer tilt correction algorithms. Boundary-Layer Meteorol. 99, 127-150. 
Wilson, K.B., Meyers, T.P., 2001. The spatial variability of energy and carbon dioxide fluxes at the floor of a deciduous forest. Boundary-Layer Meteorol. 98, 443-473.

Xu, L., Furtaw, M.D., Madsen, R.A., Garcia, R.L., Anderson, D.J., McDermitt, D.K., 2006. On maintaining pressure equilibrium between a soil $\mathrm{CO}_{2}$ flux chamber and the ambient air. J. Geophys. Res., D08S10, http://dx.doi.org/10.1029/2005JD006435.

Yao, Z.S., Zheng, X.H., Xie, B.H., Liu, C.Y., Mei, B.L., Dong, H.B., Butterbach-Bahl, K., Zhu, J.G., 2009. Comparison of manual and automated chambers for field measurements of $\mathrm{N}_{2} \mathrm{O}, \mathrm{CH}_{4}, \mathrm{CO}_{2}$ fluxes from cultivated land. Atmos. Environ. 43, 1888-1896.
Zheng, X.H., Han, S.H., Huang, Y., Wang, Y.S., Wang, M.X., 2004. Re-quantifying the emission factors based on field measurements and estimating the direct $\mathrm{N}_{2} \mathrm{O}$ emission from Chinese croplands. Global Biogeochem. Cycles 18, GB2018, http://dx.doi.org/10.1029/2003GB002167.

Zheng, X., Mei, B., Wang, Y., Xie, B., Wang, Y., Dong, H., Xu, H., Chen, G., Cai, Z., Yue, J., Gu, J., Su, F., Zou, J., Zhu, J., 2008. Quantification of $\mathrm{N}_{2} \mathrm{O}$ fluxes from soil-plant systems may be biased by the applied gas chromatograph methodology. Plant Soil 311, 211-314. 